\title{
Regional differences in the timing of the spring bloom in the Labrador Sea
}

\author{
Yongsheng Wu ${ }^{1, *}$, Trevor Platt ${ }^{1}$, Charles C. L. Tang ${ }^{1}$, Shubha Sathyendranath ${ }^{1,2}$ \\ ${ }^{1}$ Coastal Ocean Science, Bedford Institute of Oceanography Dartmouth, Nova Scotia, B2Y 4A2, Canada \\ ${ }^{2}$ Plymouth Marine Laboratory, Prospect Place, The Hoe, Plymouth PL1 3DH, UK
}

\begin{abstract}
The environmental factors that control the timing of the spring bloom in the Labrador Sea were investigated using ocean color data from satellites, historical oceanographic data and a primary production model. From the satellite data, the onset of the spring bloom was found to progress with the season from south to north, with the exception of the northern Labrador Sea. The onset for the northern Labrador Sea occurred at approximately the same time as in the southern Labrador Sea. Two possible factors for the regional differences were examined from the data: irradiance and mixedlayer depth (MLD). The early bloom in the northern Labrador Sea is related to the very shallow mixed layer associated with low-salinity water. The temporal variations of the mean chlorophyll concentration in 4 regions of the Labrador Sea (the Grand Banks, southern, central and northern Labrador Sea) during the growth phase of the spring bloom were modeled using a primary production model with MLD derived from historical temperature-salinity data. The temporal variations, in particular the early bloom in the northern Labrador Sea, were well reproduced by the model. A model sensitivity study showed that the onset of the spring bloom is highly sensitive to MLD. This confirms the finding from the data that MLD is a critical environmental factor for the spring bloom. The availability of the photosynthetically active radiation plays an important role, but is not a determining factor of the early bloom in the northern Labrador Sea. The sensitivity study also showed that pre-bloom oceanographic conditions and attenuation of light in water have a greater effect on the timing in a shallow mixed layer than in a deeper mixed layer.
\end{abstract}

KEY WORDS: Spring bloom · Onset time $\cdot$ Mixed layer depth $\cdot$ Regional difference $\cdot$ Labrador Sea

\section{INTRODUCTION}

The spring bloom of phytoplankton is the main pulse in the seasonal dynamics of the marine ecosystem in temperate latitudes. The timing of the bloom is one of the critical factors that regulate the ecological cycle of the ocean. The classical explanation for the occurrence of spring blooms is Sverdrup's (1953) critical depth theory. The critical depth is defined as that at which the vertically averaged production is balanced by the vertically averaged loss. When the mixed-layer depth is deeper than the critical depth, the phytoplankton concentration in the surface layer is diluted within the mixed-layer. Thus the mean irradiance for photosynthesis is reduced. When the mixed-layer depth decreases from winter to spring, the phytoplankton concentration in the surface layer has more opportunity to exploit the increased irradiance. The net growth of phytoplankton begins when the mixed layer becomes shallower than the critical depth.

During the spring, increasing solar radiation can promote both photosynthesis and stratification of the water column. Thus, it is widely accepted that the spring bloom propagates from low to high latitude after the establishment of seasonal thermal stratification. However, recent observations indicate that mechanisms other than heat input might play a more important role for water stratification and lead to spring blooms. For example, surface freshening by river runoff, precipitation and ice-melt can also contribute to 
the upper ocean stratification and trigger spring blooms (Sinclair 1978, Campbell \& Aarup 1992, Lucas et al. 1998, Dutkiewicz et al. 2001, Labry et al. 2001, Stramska 2005, Waniek et al. 2005). Townsend et al. (1992) and Eilertsen (1993) reported that blooms occurred in the absence of vertical stratification. These observations suggest that mechanisms triggering spring blooms may differ from region to region.

The seasonal cycle of phytoplankton in the Labrador Sea and its ecological significance have been studied by a number of authors (e.g. Campbell \& Aarup 1992, Head et al. 2000, Afanasyev et al. 2001, Pedersen et al.
2005). Recent remotely sensed chlorophyll composites show that the initiation time of the spring bloom in this area is strongly regionally dependent. The horizontal distribution of bi-weekly composite chlorophyll concentration from March to June is shown in Fig. 1. There are 2 clearly separated areas of high chlorophyll concentration. In the south, the broad pattern of the spring bloom begins on the Grand Banks at the end of March, and then moves and expands to the southern and the central Labrador Sea. In the northern Labrador Sea, the bloom starts in early April. The onset times in the southern and northern areas are earlier than in the
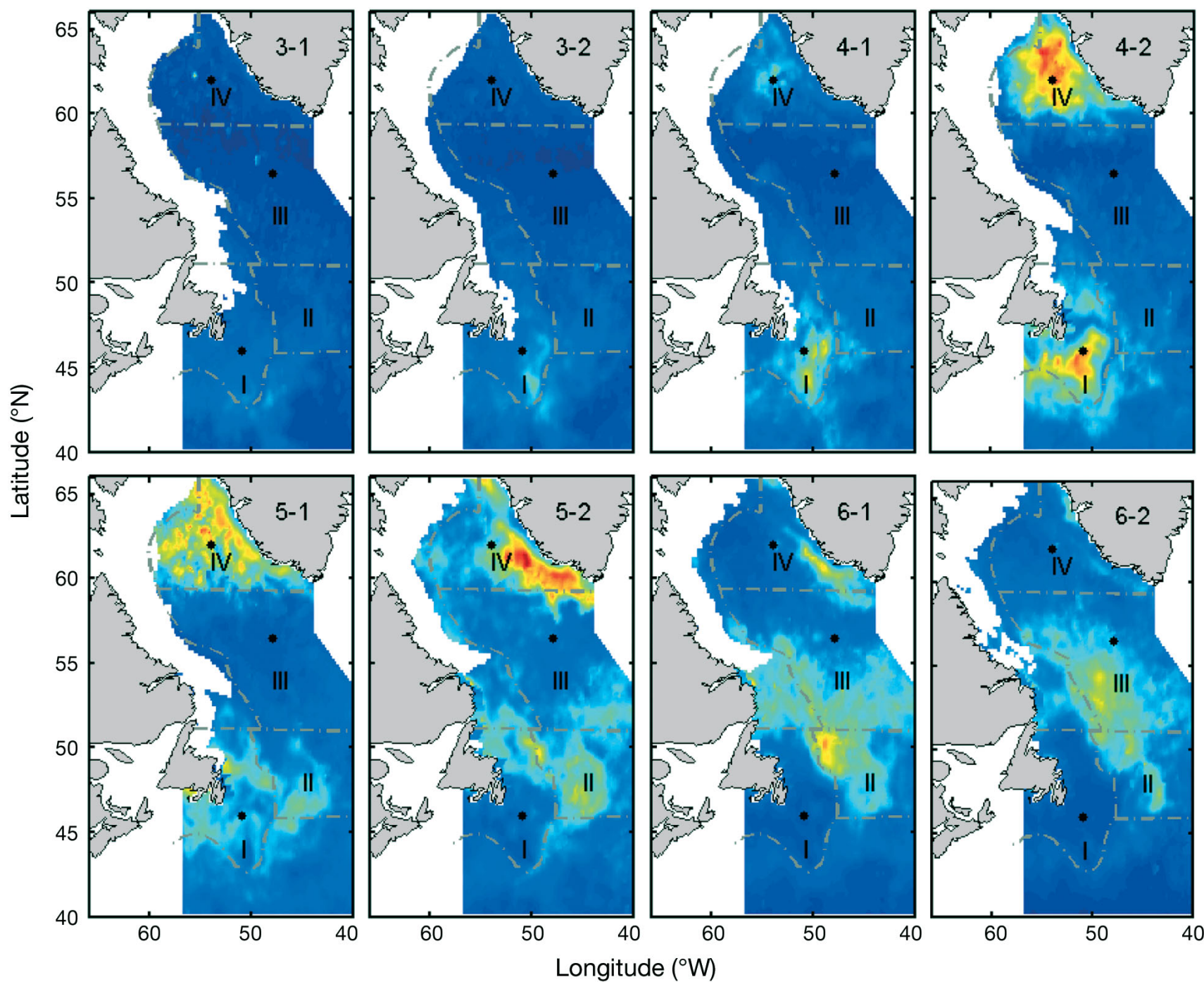

Longitude $\left({ }^{\circ} \mathrm{W}\right)$

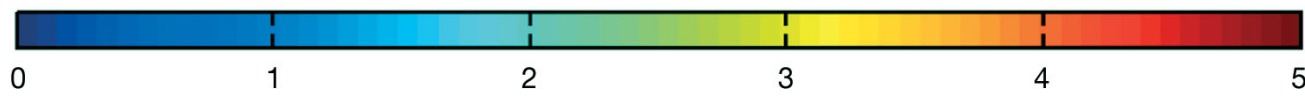

$\mathrm{Chl}\left(\mathrm{mg} \mathrm{m}^{-3}\right)$

Fig. 1. Six-year (1998-2003) bi-weekly composite chlorophyll concentrations based on SeaWiFS data from March to June. Inside each panel, the month is indicated by the first arabic number followed by -1 (first half of the month), or -2 (second half of the month). Regions are I - the Grand Banks; II — the southern Labrador Sea; III — the central Labrador Sea; and IV — the northern Labrador

Sea. : arrayed from south to north are the locations for Figs. 5 to 7 for the Grand Banks, central and northern Labrador Sea 
central part. Hitherto, these observations were unexplained. Here, we seek an explanation by combining satellite and oceanographic data, and with the use of a 1-dimensional primary production model.

\section{MATERIALS AND METHODS}

Chlorophyll data. The remotely sensed chlorophyll concentration used here is from the Sea-viewing Wide Field-of-view Sensor (SeaWiFS) data stream. The period is from 1 January 1998 to 31 December 2003. For investigation of environmental factors, we divided the Labrador Sea into 4 regions: the Grand Banks, southern Labrador Sea, central Labrador Sea and northern Labrador Sea (west of Greenland). These regions were designated as Regions I to IV (Fig. 1). We ignored the area south of the Grand Banks because there is no clear bloom in this region. Another region we ignored is the Labrador Shelf because it is covered by sea-ice from November to June.

Historical hydrographic data. To study the effects of stratification on the onset of spring blooms in different regions, historical temperature and salinity data were analyzed to obtain the mixed-layer depth. The records, which were taken from the archive of Bedford Institute of Oceanography, Dartmouth, Canada, included bottle and CTD data from the Canadian Marine Environmental Data Service and US National Oceanographic Data Center dating back to 1910. A topography-dependent iterative-difference correction method was employed to produce monthly temperature and salinity climatologies. The analysis was performed on a $1 / 12^{\circ} \times 1 / 12^{\circ}$ grid at 33 depths from $40^{\circ} \mathrm{W}$ to $95^{\circ} \mathrm{W}$ and from $35^{\circ} \mathrm{N}$ to $80^{\circ} \mathrm{N}$.

The parameter value at a grid point, $T$, was computed for each month from the following equation in 3 iterations with decreasing radii of influence:

$$
T=T_{\text {guess }}+\frac{\sum_{i} W_{i}\left(T_{i}-T_{\text {guess }, i}\right)}{\sum_{i} W_{i}}
$$

where the summation $i$ is over data points within an area defined by the radius of influence and water depths, the subscript 'guess' denotes values from the previous iteration, and $W_{i}$ is a distance dependent weight.

The objective analysis involved smoothing, averaging and interpolation of the raw data. These operations were performed with no consideration of the dynamical constraints that govern the distribution of water properties. To overcome this problem, the objectively analyzed data were input into a 3-D ocean circulation model (Princeton Ocean Model: www.aos.princeton.
edu/WWWPUBLIC/htdocs.pom/) and a 3-step spin-up run was performed for each month. This process can improve the data quality, particularly in areas of scarce observations. The output of the model spin-up included monthly 3-D temperature and salinity fields, which are used in the discussions in the following sections. The 3-D ocean circulation model used in the spin-up covers the area $40^{\circ}-68^{\circ} \mathrm{N}, 40^{\circ}-68^{\circ} \mathrm{W}$ and has a grid size of $1 / 5^{\circ}$ (longitude) $\times 1 / 6^{\circ}$ (latitude) and 29 vertical depth levels. The coordinate system is Cartesian coordinates in the horizontal plane and terrainfollowing sigma coordinates in the vertical. At open ocean boundaries, volume transports were specified according to observations and large-scale models. Sea level and the normal component of the velocity were calculated from the prescribed volume transports and density data. The details of the model setup and methods of computation are given in Yao et al. (2000).

We used the temperature-salinity data described above to determine the mixed-layer depth (MLD) in the study area for each month. A common method is to find the depth at which the density or temperature changes from surface values reach a preset criterion. We used a density change of $0.07 \mathrm{~kg} \mathrm{~m}^{-3}$ to generate MLD. The impact of the uncertainty in MLD on our analysis is discussed in the 'Vertical structure' and 'Sensitivity study' sections below.

Model. Model equations: A 1-D primary production model is employed here to calculate the mean chlorophyll concentration as a function of time during the initial phase of the chlorophyll cycle in different regions of the Labrador Sea. The results are compared with the observed chlorophyll concentration shown in Fig. 2. The model is based on the one-dimensional model for primary production developed by Platt et al. (1991a), in which the local change of biomass (indexed as chlorophyll concentration) is controlled by photosynthetic growth and losses due to respiration, zooplankton grazing, sinking and vertical mixing. To keep the model as simple as possible, yet retain the key factors of the biological processes, we assumed that there is no nutrient limitation to the development of the spring bloom (Platt et al. 1991a, 1994, Stramska \& Dickey 1994, Lucas et al. 1998). The horizontal advection of phytoplankton is also ignored in our 1-D model since we assume changes in chlorophyll concentration are controlled primarily by physical and biological processes in the vertical plane.

The conservation equation for chlorophyll concentration is written as

$$
\frac{\partial B}{\partial t}=\frac{\partial}{\partial z} v_{t} \frac{\partial B}{\partial z}+G-L+w_{\mathrm{s}} \frac{\partial B}{\partial z}
$$

where $B$ is chlorophyll concentration in $\mathrm{mg} \mathrm{m}^{-3}, w_{\mathrm{s}}$ is the sinking velocity in $\mathrm{m} \mathrm{d}^{-1}, v_{t}\left(\mathrm{~m}^{2} \mathrm{~s}^{-1}\right)$ is the vertical 


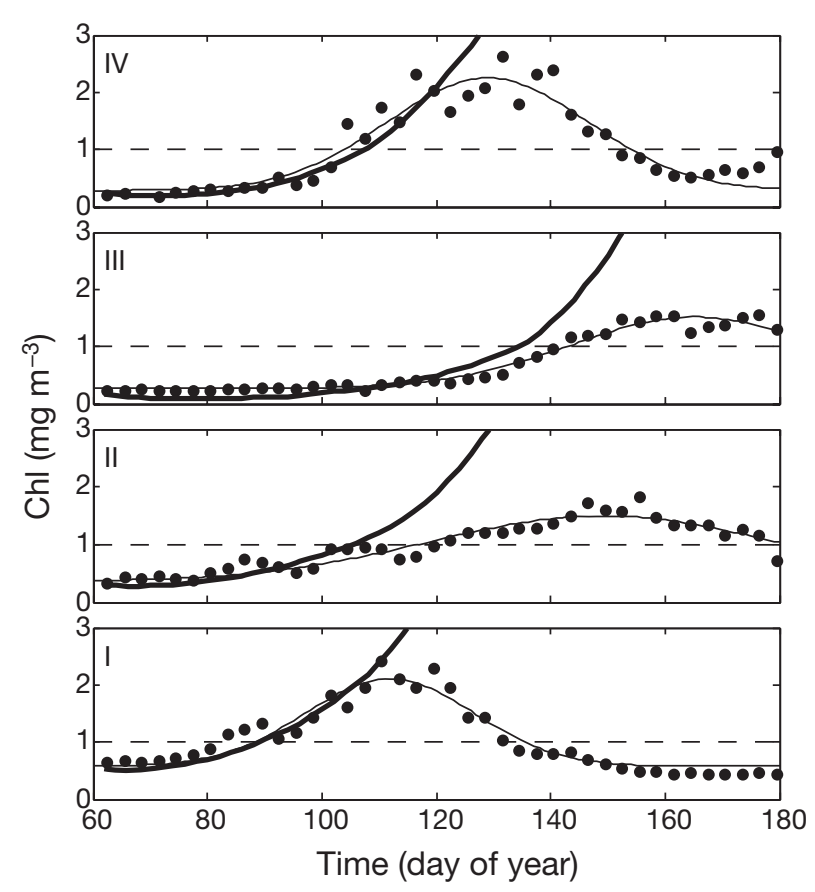

Fig. 2. Regionally averaged chlorophyll concentration of climatology (1998-2003) of 3 d composites ( $\bullet$ ) for the 4 study regions (I to IV, see Fig. 1) and model results (—). - is the fitted curve for data, and ---- is $1.0 \mathrm{mg} \mathrm{m}^{-3}$ level

diffusion coefficient, $z$ is depth (downward is positive), $G$ and $L$ are the growth and loss terms, respectively.

The water column is assumed to consist of an upper mixed layer and a deep layer. The chlorophyll concentration in the mixed layer is assumed to be uniform. Integrating Eq. (1) from the surface to the base of the mixed layer, $z=H$, we have

$$
\frac{\partial B_{0}}{\partial t}=\frac{1}{H} \int_{0}^{H} G \mathrm{~d} z-\frac{1}{H} \int_{0}^{H} L \mathrm{~d} z-\frac{W_{\mathrm{s}} B_{0}}{H}
$$

where $B_{0}$ is the chlorophyll concentration in the mixed layer. The diffusion term in Eq. (2) disappears after the integration because there is no chlorophyll flux at the sea surface or at the base of the mixed layer during mixed-layer shallowing. At a given location, $B_{0}$ as a function of time can be obtained by integrating Eq. (3) from a pre-set start time. The resulting $B_{0}$ is then averaged over each of the 4 regions shown in Fig. 1 to obtain the mean concentration.

Growth: Based on experiments in which phytoplankton samples are incubated in a gradient of light, a representation of the dependence of photosynthesis on irradiance (P-I curve) was proposed by Platt et al. (1980):

$$
G(z)=\frac{B(z)}{\chi} \cdot P_{\mathrm{m}}^{B}\left[1-\exp \left(-\alpha^{B} I(z) / P_{\mathrm{m}}^{B}\right)\right]
$$

where $P_{\mathrm{m}}^{B}\left(\mathrm{mg} \mathrm{C}[\mathrm{mg} \mathrm{chl}]^{-1} \mathrm{~h}^{-1}\right)$ is the assimilation number, $\alpha^{B}\left(\mathrm{mg} \mathrm{C}[\mathrm{mg} \mathrm{chl}]^{-1} \mathrm{~h}^{-1}\left[\mathrm{~W} \mathrm{~m}^{-2}\right]^{-1}\right)$ is the initial slope of the P-I curve, $I\left(\mathrm{~W} \mathrm{~m}^{-2}\right)$ is the local photosynthetically active radiation (PAR), $\chi\left(\mathrm{mg} \mathrm{C}\left[\mathrm{mg} \mathrm{chl}^{-1}\right.\right.$ ) is the carbon to chlorophyll ratio. For simplicity, we use a constant value of $\chi=50$ (Stramska \& Dickey 1994).

Eq. (4) is an approximation in that it ignores wavelength-dependent effects. As explained by Sathyendranath et al. (1989), the error due to suppression of wavelength effect overestimates primary production by $60 \%$ at high chlorophyll concentrations and underestimates it slightly (by $6 \%$ ) at low chlorophyll concentrations. To take the wavelength-dependent effect into account, we replaced Eq. (4) by the following equations in our model:

$$
G(z)=\frac{B(z)}{\chi} \cdot P_{\mathrm{m}}^{B}\left[1-\exp \left(-\Pi(z) / P_{\mathrm{m}}^{B}\right)\right]
$$

$\Pi(z)=\sec \theta \int \alpha^{B}(z, \lambda) I_{\mathrm{d}}(z, \lambda) \mathrm{d} \lambda+1.2 \int \alpha^{B}(z, \lambda) I_{\mathrm{s}}(z, \lambda) \mathrm{d} \lambda$

where the parameters $\lambda$ and $\theta$ are the wavelength $(400-700 \mathrm{~nm})$ and the zenith angle, respectively, $\alpha^{B}$ is the weighted light-limited rate of photosynthesis over the wavelength range, $I_{\mathrm{d}}$ and $I_{\mathrm{s}}$ are the direct and diffuse components of irradiance, where values at sea surface are calculated from Bird (1984). The details of the derivation and calculation of Eqs. (5) \& (6) can be found in Sathyendranath et al. (1989).

Radiation is a major source of surface heating in spring and summer and contributes to the stratification of the upper ocean. Its magnitude decreases with increasing cloud cover. There is an empirical relationship between irradiance and cloud fraction. In the model, the effect of cloud cover on irradiance is estimated following the method of Platt et al. (1991b), with a mean cloud fraction of 0.75 . This value is based on the cloud data from National Centers for Environmental Prediction (DeTracey \& Tang 1997). Below the ocean surface, irradiance decreases exponentially with depth:

$$
I_{n}(z, \lambda)=I_{n}(0, \lambda) \cdot \mathrm{e}^{-\int_{0}^{L} k(z, \lambda) \mathrm{d} z}
$$

where the subscript $n=d$ or $s, I_{\mathrm{d}}(0, \lambda)$ and $I_{\mathrm{s}}(0, \lambda)$ are the surface values of direct and diffuse irradiance at wavelength $\lambda$, respectively; $k(z, \lambda)$ is the wavelengthdependent vertical attenuation coefficient calculated from the model of Sathyendranath \& Platt (1988).

The values of the photosynthetic parameters $P_{\mathrm{m}}^{B}$ and $\alpha^{B}$ used in the 4 regions of our model domain were assigned according to Platt et al. (1991b), where the P-I parameters for the biological provinces of the North Atlantic were extrapolated from in situ data collected from different regions and seasons. The values for $P_{\mathrm{m}}^{B}$ and $\alpha^{B}$ in 4 regions are listed in Table 1.

Loss: The loss term consists of algal respiration, excretion and grazing by zooplankton: 


$$
L=r+\frac{e \times B}{\chi}+g \cdot B
$$

where the terms on the right-hand side represent respiration, excretion and grazing, respectively. The expression for the respiration term (Platt et al. 1991a) is:

$$
r=\frac{R_{0}^{B} \times B}{\chi}+\left(R_{\mathrm{D}}+R_{\mathrm{L}}\right) \cdot G
$$

where $R_{0}^{B}$ (mg C [mg chl $]^{-1} \mathrm{~h}^{-1}$ ) is biomass-specific dark respiration at zero growth, the dimensionless parameter $R_{\mathrm{D}}$ is the linear coefficient of increase in biomass-specific dark respiration with the growth rate, and $R_{\mathrm{L}}$ is also a dimensionless parameter representing the coefficient of the increase in respiration in light. As no field data were available, all the loss parameters were assumed equal throughout the model domain. Their values are given in Table 2 .

Model implementation: Eq. (2) was integrated from 1 March to 30 June. The time step was $1 \mathrm{~h}$. Following Evans \& Parslow (1985) and Fasham et al. (1990), the mixed layer depth $H$ was prescribed. Its values were interpolated in time from the mean monthly averages to daily values. The chlorophyll concentration was initially uniform in the vertical direction, with the values given by the satellite data. For the base run, a standard set of model parameters was used (Tables $1 \& 2$ ). The uncertainties in PAR, initial condition and spectral method were examined in a sensitivity study.

\section{RESULTS}

\section{Timing of the spring bloom}

The regionally averaged chlorophyll concentrations (3-D composites over the period 1998 to 2003) in each region as a function of time are shown as a black dot $(\bullet)$ in Fig. 2. The progressive time delays of the spring bloom from south (Fig. 2 bottom panel) to north (Fig. 2 top panel) are evident from these plots except for Region IV where the onset of the spring bloom preceded that in Region III. In the following 2 sections, we discuss 2 environmental factors that are important to the spring bloom, viz. irradiance and mixed-layer depth.

\section{Irradiance}

In mid- and high-latitude oceans, it is well accepted that the availability of the PAR is the limiting factor for development of the spring bloom (Sverdrup 1953, Platt et al. 1991a). In the Labrador Sea, intensity of PAR increases from south to north as shown in Fig. 3, in which the surface PAR was calculated using the method of Bird (1984). PAR in the northern Labrador Sea is 20 to $40 \%$ lower than that in the central Labrador Sea. Assuming other conditions (mixed-layer depth, sea surface temperature, etc.) are the same, the decrease of PAR with latitude implies that the photosynthetic rate in the central Labrador Sea should be higher than in the northern Labrador Sea.

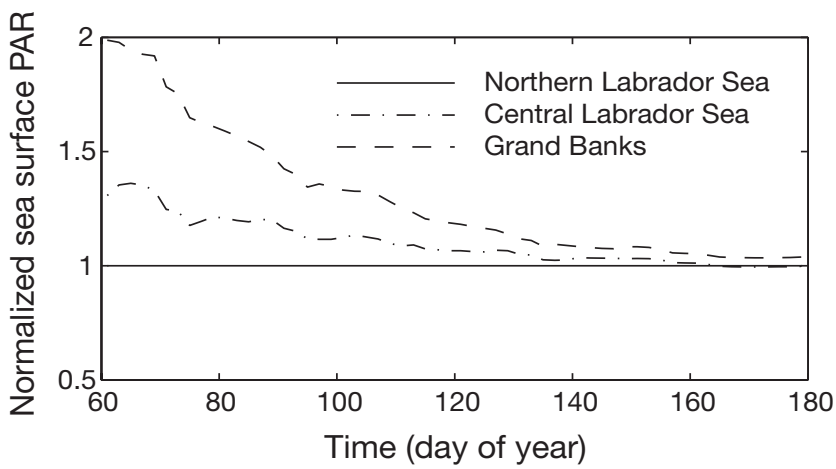

Fig. 3. Normalized irradiance for Region I (Grand Banks) and Region III (the central Labrador Sea) relative to the irradiance for Region IV (the northern Labrador Sea)

Table 1. $P_{\mathrm{m}}^{B}$ (the assimilation number) and $\alpha^{B}$ (the initial slope) values for 4 regions (I-IV) in Fig. 1 in spring (Platt et al. 1991b). Numbers in parentheses are variation (\%) of the mean values

\begin{tabular}{|lcc|}
\hline Region & $\begin{array}{c}P_{\mathrm{m}}^{B} \\
\left(\mathrm{mg} \mathrm{C}^{-1}\right. \\
{\left[\mathrm{mg} \mathrm{chl}^{-1} \mathrm{~h}^{-1}\right)}\end{array}$ & $\begin{array}{c}\alpha^{B} \\
\left(\mathrm{mg} \mathrm{C}\left[\mathrm{mg} \mathrm{chl}^{-1} \mathrm{~h}^{-1}\right.\right. \\
\left.[\mathrm{W} \mathrm{m}]^{-2}\right]^{-1}\end{array}$ \\
\hline I & $3.01(34)$ & $0.087(73)$ \\
II & $2.69(47)$ & $0.064(44)$ \\
III & $2.55(39)$ & $0.113(01)$ \\
IV & $2.55(39)$ & $0.113(01)$ \\
\hline
\end{tabular}

\begin{tabular}{|c|c|c|c|}
\hline & Parameter & Unit & Value \\
\hline$R_{0}^{B}$ & Dark respiration at zero growth & $\operatorname{mg~C}(\mathrm{mg} \mathrm{chl})^{-1} \mathrm{~h}^{-1}$ & 0.09 \\
\hline$R_{\mathrm{D}}$ & $\begin{array}{l}\text { Coefficient of the dark respiration } \\
\text { rate with growth }\end{array}$ & Dimensionless & 0.175 \\
\hline$R_{\mathrm{L}}$ & $\begin{array}{l}\text { Coefficient of respiration } \\
\text { rate in the light }\end{array}$ & Dimensionless & 0.175 \\
\hline$e$ & Excretion rate & $\mathrm{mg} \mathrm{C}(\mathrm{mg} \mathrm{chl})^{-1} \mathrm{~h}^{-1}$ & 0.05 \\
\hline$g$ & Grazing rate & $\mathrm{d}^{-1}$ & 0.13 \\
\hline$w_{\mathrm{s}}$ & Sinking velocity & $\mathrm{m} \mathrm{d}^{-1}$ & 1.0 \\
\hline$\chi$ & Carbon to chlorophyll ratio & $\mathrm{mg} \mathrm{C}(\mathrm{mg} \mathrm{chl})^{-1}$ & 50 \\
\hline
\end{tabular}

Table 2. Loss term parameter values 
However, the higher PAR does not lead to an earlier spring bloom in the central region. This suggests that there exist other controlling factors (sufficiently strong to compensate for the deficiency in PAR) that cause the early spring bloom.

\section{Mixed-layer depth and stratification}

The monthly variations of sea surface salinity, sea surface temperature and MLD for February-May are shown in Fig. 4. Low salinity water is found on the
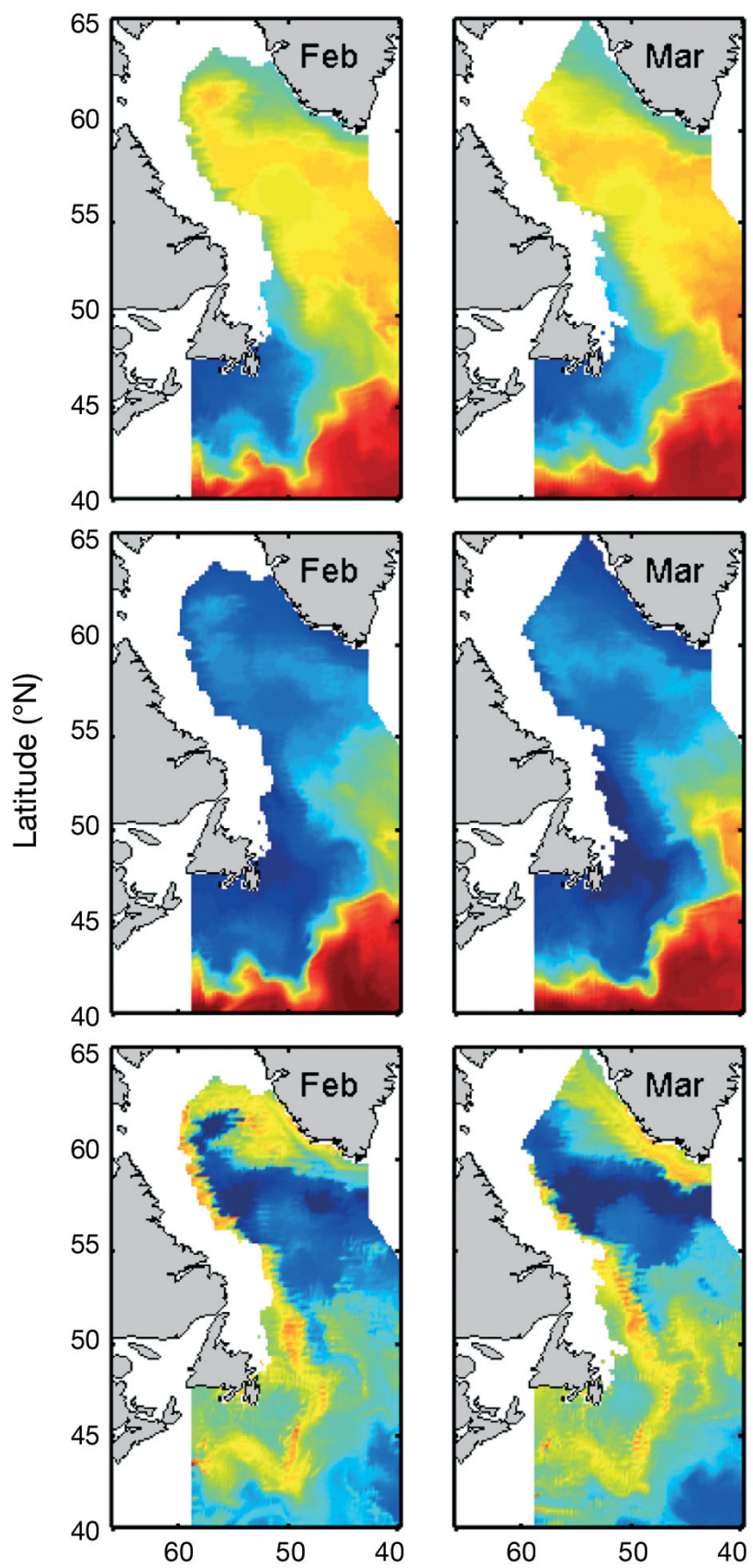

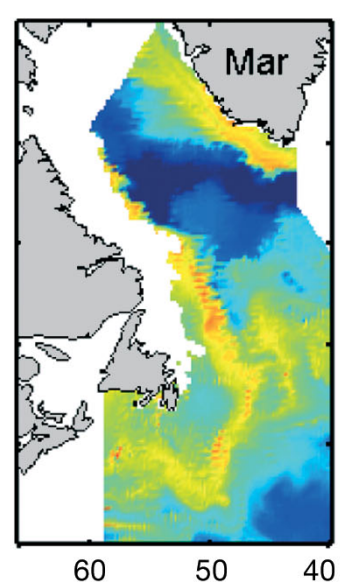

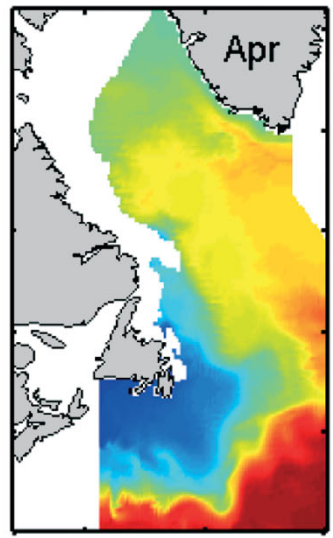
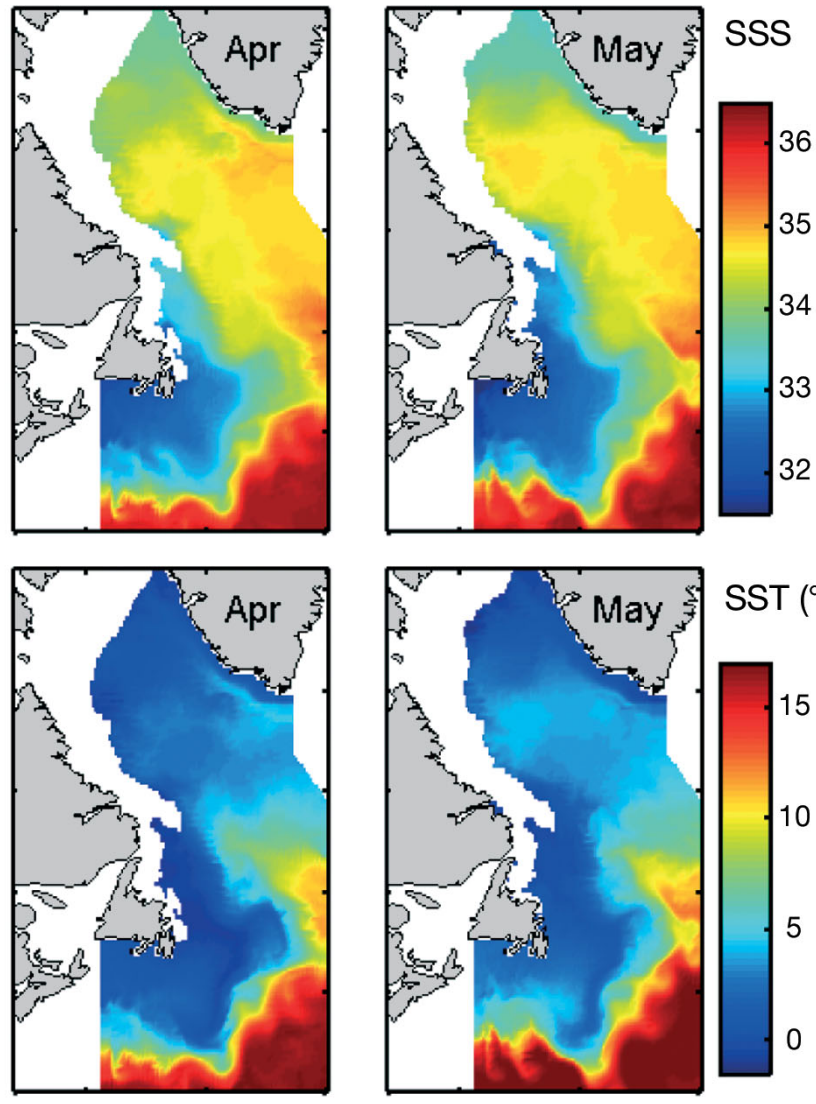

SST $\left({ }^{\circ} \mathrm{C}\right)$
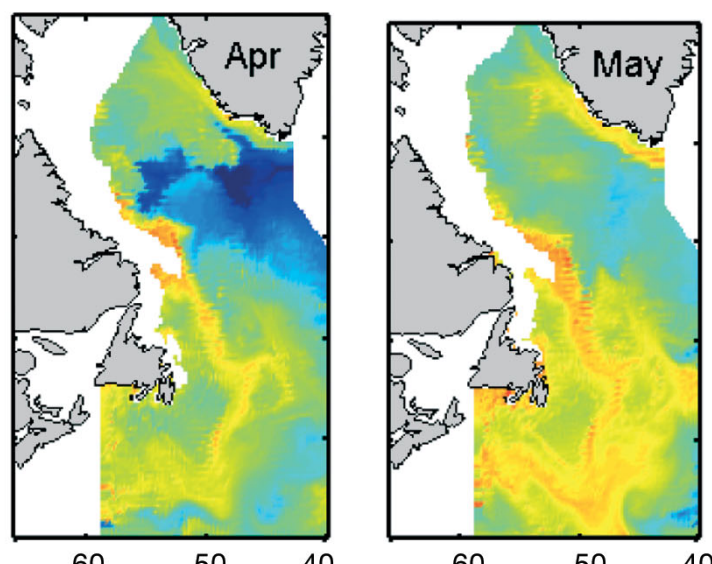

$\operatorname{MLD}(m)$

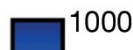

100

10

\section{1}

Longitude ( $(\mathrm{W})$

Fig. 4. Sea surface salinity (SSS) (top row), temperature (SST) $\left({ }^{\circ} \mathrm{C}\right.$, middle row) and mixed-layer depth (MLD) (m, bottom row) distribution from historical T/S (temperature/salinity) data for February, March, April and May 
Grand Banks and in the northern Labrador Sea. In general, low temperature is associated with low salinity but extends further to the south. The spatial pattern of MLD in winter is in general agreement with that reported in the model study of Tang et al. (1999) and observations of Lavender et al. (2002) in which the maximum MLD is located just off the ice edge around $58^{\circ} \mathrm{N}$ in March. A significant feature in the important period for chlorophyll growth (March and April) is the large difference in MLD between the northern and central Labrador Sea. A major contributor to the difference is salinity (Fig. 4: top row of panels). The lowsalinity water along the Greenland coast and the northern Labrador Sea is responsible for the shallow mixed layer in these areas.

Figs. 5 to 7 show the change in water properties at selected locations in Regions I, II and IV from May to June (see Fig. 1 for the locations). On the Grand Banks (Fig. 5), the vertical structure of temperature distribution suggests that the upper layer started to stratify in late March, which is also the time that the spring bloom began (vertical line). With the increase of solar heating as summer approached, the temperature increased and the thermal stratification established rapidly. The vertical salinity gradient also became stronger around this period. A major cause for the freshening of the surface water was ice melting. The

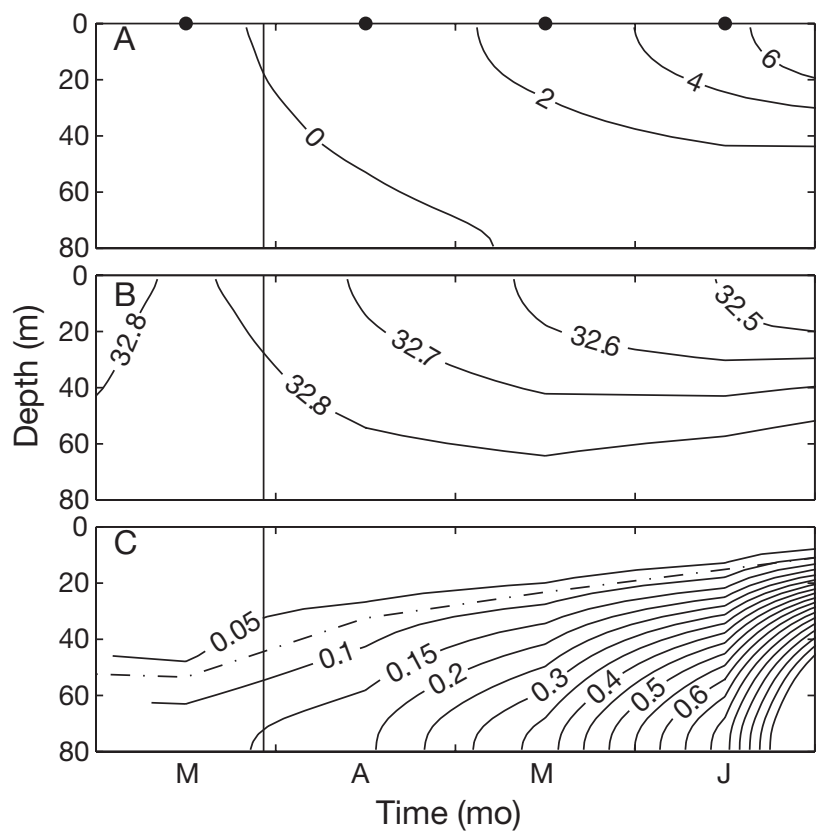

Fig. 5. (A) Temperature $\left({ }^{\circ} \mathrm{C}\right)$, (B) salinity, (C) $\Delta \sigma_{t}$ (density difference between a given depth and surface, $\mathrm{mg} \mathrm{m}^{-3}$ ) in the time-depth plane for the Grand Banks (Region I, see Fig. 1 for geographic location of the data point). -..-- in (C) is the mixed-layer depth. Vertical line indicates the onset of spring bloom, $\bullet$ in (A) indicate time of data collection pack ice over the Labrador Shelf reaches the northern Grand Banks and starts to retreat north as a result of accelerated melting at the end of March (Yao et al. 2000). The meltwater is transported to the Grand Banks by the Labrador Current and contributes to the increased stratification (Wu et al. 2007). The temperature and salinity structures suggest that the onset of the spring bloom is controlled by both thermal and salinity stratifications.

In the central Labrador Sea (Fig. 6), the vertical temperature gradient was weaker than in the Grand Banks because of the higher latitude or lower irradiance, or the combination of both factors and thus there is greater surface heat loss (Fig. 6A). The vertical salinity gradients remained weak in the entire period compared with the Grand Banks (Fig. 6B). The MLD changed from $500 \mathrm{~m}$ in winter and early spring to $20 \mathrm{~m}$ in June (Fig. 6C). It is clear that the timing of the spring bloom was more influenced by the temperature structure than by the salinity structure.

The temperature and salinity structure of the northern Labrador Sea was significantly different from that in the central Labrador Sea (Fig. 7). The surface water was colder and fresher. Strong stratification occurred throughout the entire period (Fig. 7C). The low salinity water in the upper layer dominated the density stratification since density is relatively more sensitive to

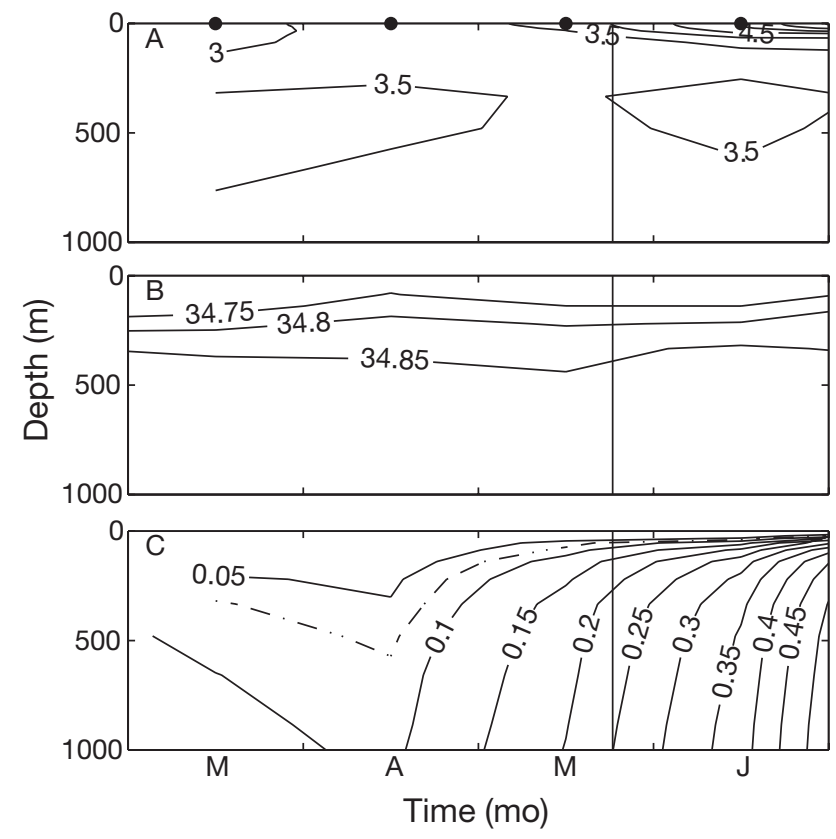

Fig. 6. (A) Temperature $\left({ }^{\circ} \mathrm{C}\right)$, (B) salinity, (C) $\Delta \sigma_{t}$ (density difference between a given depth and surface, $\mathrm{mg} \mathrm{m}^{-3}$ ) in the time-depth plane for the central Labrador Sea (Region III, see Fig. 1 for geographic location of the data point). -.-.-- in (C) is the mixed-layer depth. Vertical line indicates the onset of spring bloom, $\bullet$ in (A) indicate time of data collection 


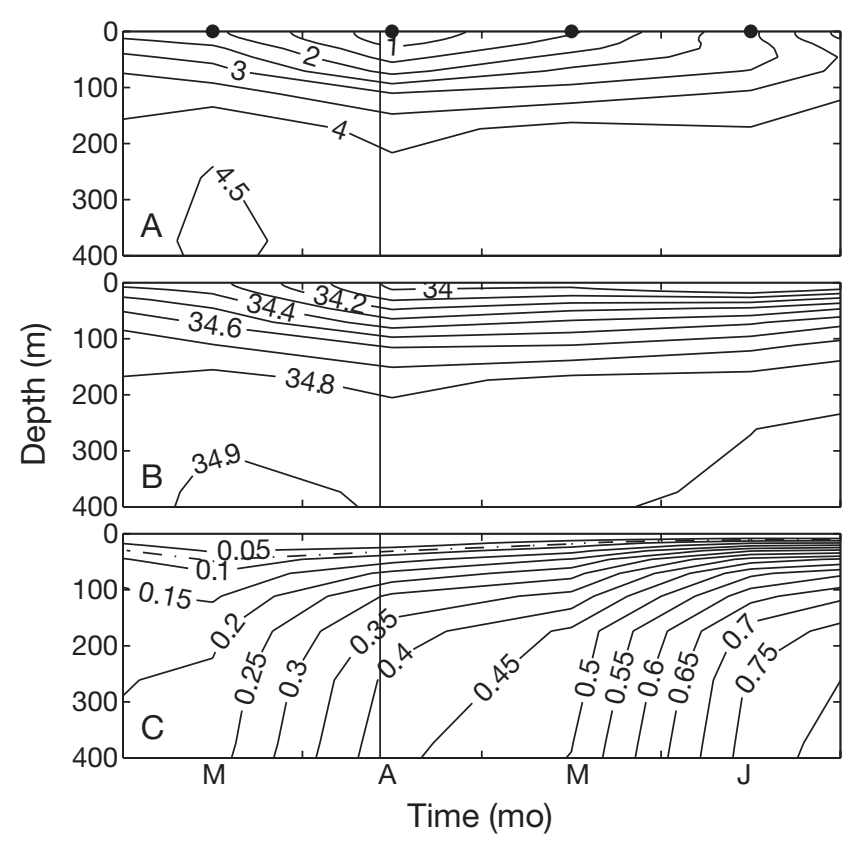

Fig. 7. (A) Temperature $\left({ }^{\circ} \mathrm{C}\right) ;$ (B) salinity; (C) $\Delta \sigma_{t}$ (density difference between a given depth and surface, $\mathrm{mg} \mathrm{m}^{-3}$ ) in the time-depth plane for the northern Labrador Sea (Region IV, see Fig. 1 for geographic location of the data point). -.-.-- in (C) is the mixed-layer depth. Vertical line indicates the onset of spring bloom, $\bullet$ in $(\mathrm{A})$ indicate time of data collection

change in salinity than to change in temperature (at low temperatures). In comparison with MLD in the central Labrador Sea, MLD in the northern Labrador Sea was shallower with a smaller range over the spring months. From the vertical section plots of $\Delta \sigma_{t}$ (bottom panels), it can be seen that the MLD was not very sensitive to the criterion defining MLD at the time of the initiation of the spring bloom and later. More importantly, regional differences in MLD (Fig. 4), the focus of our investigation, change little with the criterion.

From Region I to III, the formation of the seasonal thermocline and the shallowing of the mixed layer occurred in sequence from south to north. As these environmental factors promote phytoplankton production, a corresponding progression of the spring bloom occurred. However, in Region IV, despite the high latitude and weak irradiance, the spring bloom occurred relatively early (about the same time as Region II). The data suggest that the early formation of a shallow mixed layer due to the low-salinity surface water may have been responsible for the early bloom.

To investigate the timing of the spring bloom in a quantitative way, we use irradiance, MLD and the primary production model described in 'Materials and methods' to calculate the change of the chlorophyll concentration and compared the results with the observations (Fig. 2) in the following section.

\section{Model-data comparisons}

The comparisons of the area-averaged chlorophyll concentration from the composites of SeaWiFS data (1998 to 2003) and the results of the base run (thick lines in Fig. 2) in the 4 regions are shown in Fig. 2. The increase of chlorophyll concentration predicted by the numerical model compares well with the remote sensing data during the growth phase. Model results for the peak and declining phases of the observed spring bloom, which are not the focus of this investigation, were not expected to agree with the data because there is no nutrient limitation component in the model and the loss terms were expected to increase, leading to a decrease in chlorophyll concentration. The progressive time delay of the spring bloom from south to north and the abnormally early bloom in the northeastern Labrador Sea observed by the satellites were successfully reproduced by the model.

For the purpose of comparison, a definition for the onset of the spring bloom is required. Different definitions have been applied including the slopes of the fitted Gaussian curves, chlorophyll concentration relative to the maximum and background values. We found the results changed little with the definition. Here we use the definition of Mills et al. (1997). The onset of the spring bloom, $t_{\mathrm{sb}}$, is defined as the time when the chlorophyll concentration reaches $1.0 \mathrm{mg}$ $\mathrm{m}^{-3}$. For Regions I, II and III, the model $t_{\mathrm{sb}}$ increases from south to north. For Region IV, however, $t_{\mathrm{sb}}$ (April 13) was earlier than $t_{\mathrm{sb}}$ for Region III by $27 \mathrm{~d}$ in spite of the fact that Region IV lies $500 \mathrm{~km}$ further to the north. The shallowing of the seasonal thermocline is usually considered as a necessary condition for the spring bloom in the North Atlantic. But for Region IV, we show from the data (Fig. 4) and the model results that the earlier spring bloom is related to the fact that the mixed layer is shallower than the mixed layer in the central Labrador Sea from February to April.

\section{Sensitivity study}

To understand how the uncertainties in the model parameter values impact model results, a set of sensitivity runs was conducted. In each run, one of the model parameters was changed from the standard value in the base run. The model parameters and onset of the spring bloom $\left(t_{\mathrm{sb}}\right)$ are summarized in Table 3.

The first parameter examined is the mixed layer depth. In Runs 2 and 3, MLD = $20 \mathrm{~m}$ and $40 \mathrm{~m}$. In comparison with the base run, the spring bloom occurred earlier in all the regions for $20 \mathrm{~m}$, and earlier in the central Labrador Sea, while later in the other regions for $40 \mathrm{~m}$. The difference in $t_{\mathrm{sb}}$ between the sensitivity 
Table 3. Onset of the spring bloom $t_{s b}$ (day of year) for the 4 regions (Fig. 1). Results are from the sensitivity studies by changing the mixed-layer depth, photosynthetically active radiation, initial condition of chlorophyll and the model of the vertical attenuation coefficient. In the second column the percentage increase (+) or decrease (-) is relative to the value in the base run. Numbers in parentheses are the difference from the values in the base run, $+/-$ stand for delayed/preceding, respectively

\begin{tabular}{|c|c|c|c|c|c|}
\hline \multirow[t]{2}{*}{ Run no. } & \multirow{2}{*}{$\begin{array}{c}\text { Model } \\
\text { parameters }\end{array}$} & \multicolumn{4}{|c|}{ Timing of spring bloom (day of year) } \\
\hline & & Region I & Region II & Region III & Region IV \\
\hline${ }^{1} \operatorname{Mix}$ & $\begin{array}{c}\text { Base run } \\
\text { ed-layer depth }\end{array}$ & 89 & 105 & 134 & 107 \\
\hline 2 & 20 & $78(-11)$ & $90(-15)$ & $90(-44)$ & $94(-13)$ \\
\hline 3 & 40 & $114(+25)$ & $120(+15)$ & $108(-26)$ & $114(+7)$ \\
\hline 4 & $-20 \%$ & $84(-5)$ & $100(-5)$ & $130(-4)$ & $104(-3)$ \\
\hline 5 & $\begin{array}{c}+20 \% \\
\text { PAR }\left(W \mathrm{~m}^{-2}\right)\end{array}$ & $95(+6)$ & $111(+6)$ & $138(+4)$ & $112(+5)$ \\
\hline 6 & $-20 \%$ & $99(+10)$ & $116(+11)$ & $140(+6)$ & $114(+7)$ \\
\hline${ }^{7}$ Initial & $\begin{array}{l}+20 \% \\
l \text { value chl }(\mathrm{mg}\end{array}$ & $\begin{array}{l}83(-6) \\
\left.q^{-3}\right)\end{array}$ & $97(-8)$ & $129(-5)$ & $102(-5)$ \\
\hline 8 & $-50 \%$ & $94(+5)$ & $109(+4)$ & $136(+2)$ & $110(+3)$ \\
\hline No & $\begin{array}{c}+50 \% \\
\text { n-spectral moc }\end{array}$ & $86(-3)$ & $103(-2)$ & $133(-1)$ & $106(-1)$ \\
\hline 10 & Non-spectral & $77(-12)$ & $91(-14)$ & $133(-1)$ & $96(-11)$ \\
\hline
\end{tabular}

PAR, the spring bloom in the west Greenland region always occurred earlier than the spring bloom in the central Labrador Sea. The uncertainty in PAR gave a maximum uncertainty in $t_{\mathrm{sb}}$ of $11 \mathrm{~d}$, which was much smaller than the time difference of $27 \mathrm{~d}$ between Region III and IV in the base run.

The sensitivity of $t_{\mathrm{sb}}$ to the initial condition was examined by increasing and decreasing the initial chlorophyll concentration by $50 \%$. The general trend was that increasing the initial value caused an earlier spring bloom. Within our range, $t_{\mathrm{sb}}$ was less sensitive to the initial chlorophyll concentration than to MLD and PAR. Between the regions, $t_{\mathrm{sb}}$ was more sensitive to initial conditions in the regions with a shallow MLD (Regions I, II and IV).

Following Sathyendranath et al. (1989), the effect of the non-spectral model on the onset of the spring bloom was examined by comparing results

and the base runs depended on the magnitude of the change in MLD. For example, the onset for the central Labrador Sea occurred 44 d earlier when MLD decreased from $100 \mathrm{~m}$ (base run) to $20 \mathrm{~m}$ (Run 2). For the Grand Banks, $t_{\mathrm{sb}}$ was delayed by $25 \mathrm{~d}$ when MLD increased from $\sim 25 \mathrm{~m}$ (base run) to $40 \mathrm{~m}$ (Run 3). These results support the argument that the onset is determined mainly by MLD and irradiance (discussed later). The result also shows that the shallow MLD is the main reason for the early spring bloom in Region IV.

The results of Runs 4 and 5 show that the main findings from the base run (i.e. that $t_{\mathrm{sb}}$ for Regions I, II and III increases from south to north and $t_{\mathrm{sb}}$ for Region IV is much earlier than Region III), were not affected by an uncertainty of $\pm 20 \%$ in MLD. The maximum change in $t_{\mathrm{sb}}$ from Runs 4 and 5 was $6 \mathrm{~d}$, which is much smaller than the difference between bloom initiation in Regions III and IV in the base run.

The available PAR is another important factor for the timing of the spring bloom. There are many ways to change PAR, such as adjusting albedo and cloud cover. Since our purpose was not to investigate the individual physical processes involved, we changed PAR directly by increasing and decreasing its value by $20 \%$. In comparison with the base run, the higher PAR run (Run 7) gave an early spring bloom and the lower PAR run (Run 6) gave a late spring bloom. The magnitude of the time difference for Run 6 was greater than that for Run 7 . The change of PAR was more important for small MLD (Region I, II and IV) than for large MLD (Region III). Runs 6 and 7 showed that despite the uncertainty in from the base run and a run with the commonly used non-spectral model (Run 10), in which the vertical attenuation coefficient $\bar{K}(z)\left(\mathrm{m}^{-1}\right)$ is independent of the wavelength but varies with the chlorophyll concentration. The expression used here was $\bar{K}(z)=0.035+$ $0.04 B(z)$. Table 3 clearly shows that the onset was earlier than that of the base run in every region. Except for the central Labrador Sea, $t_{\mathrm{sb}}$ was very sensitive to $K(z)$, showing a difference of 11 to $14 \mathrm{~d}$ from the base run. In comparison, the change for the central Labrador Sea was only $1 \mathrm{~d}$. These results are consistent with the conclusion of Sathyendranath et al. (1989) that the nonspectral model overestimates primary production in areas of high chlorophyll concentration and underestimates primary production in areas of low chlorophyll concentration.

\section{DISCUSSION}

A major finding from the analysis of the chlorophyll data and the numerical model is that the spring blooms off the west Greenland coast and in the northern Labrador Sea occur a month earlier than the spring bloom in the central Labrador Sea despite the higher latitude. We show that the shallow mixed layer in the northern Labrador Sea is mainly responsible for the early bloom. The shallow mixed layer is associated with low-salinity water along the Greenland coast. Possible sources of the low-salinity and freshwater include the East Greenland Current (EGC) and local precipitation. 


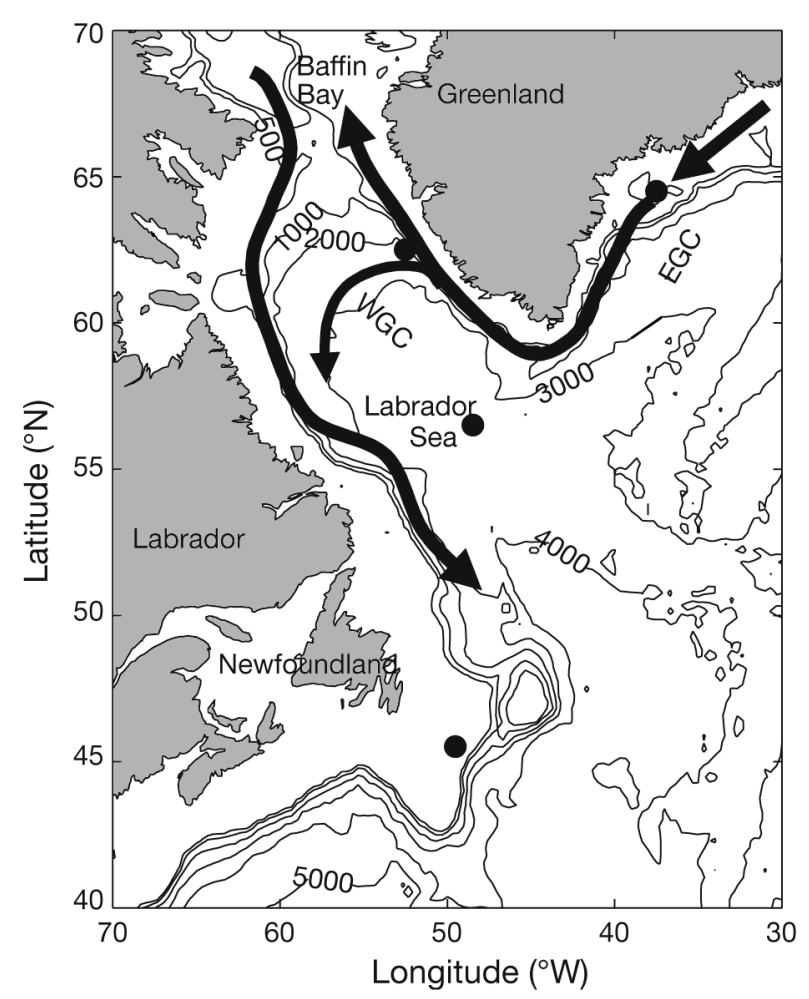

Fig. 8. Schematic representation of the circulation of northwestern North Atlantic Ocean. The solid circles are the locations for the precipitation data in Fig. 9: the western Greenland coast, the eastern Greenland coast, the central Labrador Sea and the Grand Banks. EGC: East Greenland Current, WGC: West Greenland Current

The East Greenland Current flows southward along the east coast of Greenland (Fig. 8). At Cape Farewell (the southern tip of Greenland), it turns west then north into the Labrador Sea, forming the West Greenland Current (WGC) (Ezer \& Mellor 1994). The EGC transports Arctic Ocean water masses, most of the ice exported from the Arctic Ocean and recirculating Atlantic water (Woodgate et al. 1999). Owing to its Arctic origin and ice melt, the water of EGC is fresher and colder than the surrounding waters. The link between the waters of EGC and the northern Labrador Sea is WGC, which flows north along the west coast of Greenland (Fig. 8). Energetic ocean eddies are generated along the path of the current; the eddies mix the waters of WGC and the northern Labrador Sea (Prater 2002). At 62 to $64^{\circ} \mathrm{N}$, the WGC turns west to cross the Labrador basin. A small branch of WGC flows north through the Davis Strait into Baffin Bay (Tang et al. 2004). Horizontal advection and mixing spread the low salinity water from the Greenland coast to the northern Labrador Sea, creating a shallow mixed layer.

Another source of fresh water is atmospheric precipitation. The precipitation rate along the Greenland

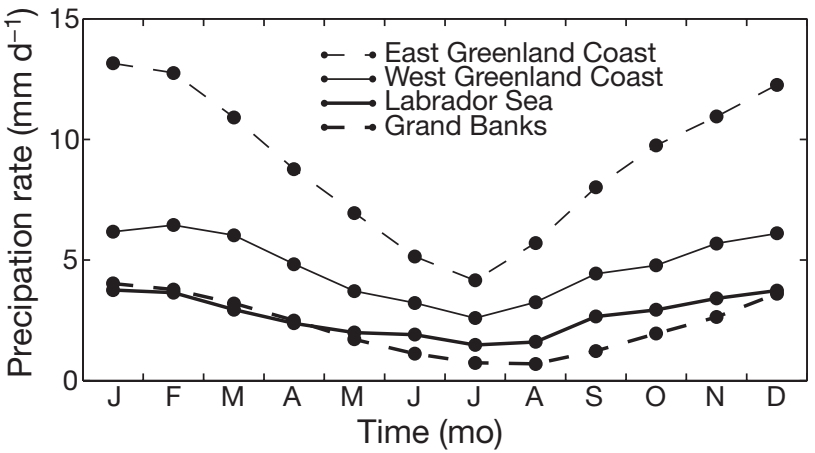

Fig. 9. Mean annual precipitation rate from the National Centers for Environmental Prediction (DeTracey \& Tang 1997). The locations are shown in Fig. 8

coast south of $67^{\circ} \mathrm{N}$ is much higher than that in the adjacent areas (Ohmura \& Reeh 1991, Chen et al. 1997, Bromwich et al. 1999). A comparison of the annual cycle of precipitation off the Greenland coast and other regions is presented in Fig. 9. The curves are climatological precipitation rates based on data from National Centers for Environmental Prediction (NCEP: see www.emc.ncep.noaa.gov/). The high precipitation rate can decrease the salinity in WGC and EGC and contribute to the low salinity and shallow MLD in Region IV. The cause for the high precipitation rate in southern Greenland, however, is beyond the scope of this paper.

\section{CONCLUSIONS}

Chlorophyll data from satellites were analyzed to study initiation of the spring bloom in the Labrador Sea and the environmental factors that control its timing. The study area was divided into 4 regions: the Grand Banks, the southern Labrador Sea, the central Labrador Sea and the northern Labrador Sea. From composite chlorophyll data, the onset of the spring bloom was found to progress with the season from south to north with the exception of the northern Labrador Sea. The onset for the northern Labrador Sea occurred at approximately the same time as that of the southern Labrador Sea. Two factors for the regional differences were examined: irradiance and mixed-layer depth. The early bloom in the northern Labrador Sea is shown to be related to the very shallow mixed layer off the Greenland coast and in the northern Labrador Sea. The initiation of the spring bloom in the other 3 regions is linked to the development of the seasonal thermocline.

The spring bloom in the Labrador Sea was simulated numerically by a simple 1-dimensional primary production model in which biological productivity and loss, photosynthetically active radiation (PAR) and 
mixed-layer depth (MLD) were included, but nutrient limitation ignored. The MLD data were based on the monthly climatology of temperature and salinity. The model-simulated chlorophyll concentrations were in good agreement with the data in the initial (growth) phase of the chlorophyll cycle. The model results showed that, except for the northern Labrador Sea, the bloom onset is approximately in phase with the formation of the seasonal thermal stratification established by surface heating. The spring bloom in the northern Labrador Sea starts in mid-April when the thermal stratification has not yet been established because of the high latitude. The shallow mixed layer there plays a more important role than solar radiation in the development of the spring bloom. It is associated with lowsalinity water along the Greenland coast and in the northern Labrador. Two mechanisms are proposed to explain the low salinity water. One is the horizontal advection of low salinity water carried by the EGC, WGC and the westward extension of the WGC around 62 to $64^{\circ} \mathrm{N}$. The other is the high precipitation rate along the coast of southern Greenland.

In addition to MLD, we also used the model to examine pre-bloom chlorophyll concentration and the parameterization of PAR. The onset of the spring bloom was shown to be sensitive to the PAR availability, but light is not a determining factor for the early bloom in the northern Labrador Sea. Pre-bloom conditions, PAR and the attenuation property of light in water have a greater effect on the timing of the spring bloom in shallow mixed layers than in deeper mixed layers.

Acknowledgements The research was supported by the Canadian Space Agency under the Ocean's Pulse (TOP) project (GRIP) and the Program for Energy Research and Development (PERD). The authors thank G. White III for preparing the biological datasets used in this paper. We are grateful to 2 anonymous reviewers for their comments which improved the manuscript. We also thank B. Greenan and E. Devred for helpful comments on an early version of the manuscript.

\section{LITERATURE CITED}

Afanasyev YD, Nezlin NP, Kostianoy AG (2001) Patterns of seasonal dynamics of remotely sensed chlorophyll and physical environment in the Newfoundland region. Remote Sens Environ 76:268-282

Bird RE (1984) A simple, solar spectral model for directnormal and diffuse horizontal irradiance. Solar Energy 32: 461-471

Bromwich DH, Chen Q, Li Y, Cullather RI (1999) Precipitation over Greenland and its relation to the North Atlantic Oscillation. J Geophys Res 104:22103-22115

Campbell JW, Aarup T (1992) New production in the North Atlantic derived from seasonal patterns of surface chlorophyll. Deep-Sea Res 39:1669-1694

Chen Q, Bromwich DH, Bai L (1997) Precipitation over Greenland retrieved by a dynamic method and its relation to cyclonic activity. J Clim 10:839-870
DeTracey BM, Tang CL (1997) Monthly climatological atlas of surface atmospheric conditions of the Northwest Atlantic. Can Data Rep Hydrog Ocean Sci 152:1-63

Dutkiewicz S, Follows M, Marshall J, Gregg WW (2001) Interannual variability of phytoplankton abundances in the North Atlantic. Deep-Sea Res II 48:2323-2344

Eilertsen HC (1993) Spring blooms and stratification. Nature 363:24-24

Evans GT, Parslow J (1985) A model of annual plankton cycles. Biol Oceanogr 3:327-347

Ezer T, Mellor GL (1994) Diagnostic and prognostic calculations of the North Atlantic circulation and sea level using a sigma coordinate ocean model. J Geophys Res 99: 14159-14171

Fasham MJR, Ducklow HW, Mckelvie SM (1990) A nitrogenbased model of plankton dynamics in the oceanic mixed layer. J Mar Res 48:591-639

Head EJH, Harris LR, Campbell RW (2000) Investigations on the ecology of Calanus spp. in the Labrador Sea. I. Relationship between the phytoplankton bloom and reproduction and development of Calanus finmarchicus in spring. Mar Ecol Prog Ser 193:53-73

Labry C, Herbland A, Delmas D, Laborde P and others (2001) Initiation of winter phytoplankton blooms within the Gironde plume waters in the Bay of Biscay. Mar Ecol Prog Ser 212:117-130

Lavender KL, Davis RE, Owens WB (2002) Observations of open-ocean deep convection in the Labrador Sea from subsurface floats. J Phys Oceanogr 32:511-526

Lucas L, Cloern JE, Koseff JR, Monismith SG, Thompson JK (1998) Does the Sverdrup critical depth model explain bloom dynamics in estuaries? J Mar Res 56:375-415

Mills DK, Gowen RJ, Woods EA (1997) Observation and simulation of the spring bloom in the north-western Irish Sea. J Plankton Res 19:63-77

Ohmura A, Reeh N (1991) New precipitation and accumulation maps for Greenland. J Glaciology 37:140-148

Pedersen SA, Ribergaard MH, Simonsen CS (2005) Microand mesozooplankton in Southwest Greenland waters in relation to environmental factors. J Mar Syst 56:85-112

Platt T, Gallegos CL, Harrison WG (1980) Photoinhibition of photosynthesis in natural assemblages of marine phytoplankton. J Mar Res 38:687-701

Platt T, Bird D, Sathyendranath S (1991a) Critical depth and marine primary production. Proc R Soc Lond B 246: 205-217

Platt T, Caverhill C, Sathyendranath S (1991b) Basin-scale estimates of oceanic primary production by remote sensing: the North Atlantic. J Geophys Res 96:15147-15159

Platt T, Woods JD, Sathyendranath S, Barkmann W (1994) Net primary production and stratification in the ocean. Geophys Monogr 85:247-254

Prater MD (2002) Eddies in the Labrador Sea as observed by profiling RAFOS floats and remote sensing. J Phys Oceanogr 32:411-427

Sathyendranath S, Platt T (1988) The spectral irradiance field at the surface and in the interior of the ocean: a model for applications in oceanography and remote sensing. J Geophys Res 93:9270-9280

Sathyendranath S, Platt T, Caverhill CM, Warnock RE, Lewis MR (1989) Remote sensing of oceanic primary production: computations using a spectral model. Deep-Sea Res 36: 431-453

Sinclair M (1978) Summer phytoplankton variability in the lower St. Lawrence estuary. J Fish Res Board Can 35: $1171-1185$

Stramska M (2005) Interannual variability of seasonal phyto- 
plankton blooms in the north polar Atlantic in response to atmospheric forcing. J Geophys Res 110:C05016, doi: 10.1029/2004JC002457

Stramska M, Dickey TD (1994) Modelling phytoplankton dynamics in the northeast Atlantic during the initiation of the spring bloom. J Geophys Res 99:10241-10253

Sverdrup HU (1953) On conditions for the vernal blooming of phytoplankton. J Cons Perm Int Explor Mer 18:287-295

Tang CL, Gui Q, DeTracey BM (1999) A modelling study of upper ocean winter processes in the Labrador Sea. J Geophys Res 104:23411-23425

Tang CL, Ross CK, Yao T, Petrie B, Detracey BM, Dunlap E (2004) The circulation, water masses and sea-ice of Baffin Bay. Prog Oceanogr 63:183-228

Townsend DW, Keller MD, Sieracki ME, Ackleson SG (1992) Spring phytoplankton blooms in the absence of vertical

Editorial responsibility: Howard Browman, Storebø, Norway water column stratification. Nature 360:59-62

Waniek JJ, Holliday NP, Davidson R, Brown L, Henson SA (2005) Freshwater control of onset and species composition of Greenland shelf spring bloom. Mar Ecol Prog Ser 288:45-57

Woodgate RA, Fahrbach E, Rohardt G (1999) Structure and transport of the East Greenland Current at $75^{\circ} \mathrm{N}$ from moored current meters. J Geophys Res 104:18059-18072

Wu YS, Peterson IK, Tang CL, Platt T, Sathyendranath S, Fuentes-Yaco C (2007) The impact of sea-ice on the spring bloom on the Labrador and Newfoundland Shelves. J Plankton Res 29:509-514.

Yao T, Tang CL, Peterson IK (2000) Modeling the seasonal variation of sea ice in the Labrador Sea with a coupled multicategory ice model and the Princeton ocean model. J Geophys Res 105:1153-1166

Submitted: January 12, 2007; Accepted: September 3, 2007 Proofs received from author(s): February 5, 2008 